\title{
Nutritional status in patients on left ventricular assist device support
}

\author{
Nicholas C. Dang, MD, Veli K. Topkara, MD, Brian T. Kim, BS, Brian J. Lee, BS, Romolo Remoli, \\ and Yoshifumi Naka, MD, PhD, New York, NY
}

T he presence of malnutrition and cachexia in patients with congestive heart failure is well documented. ${ }^{1,2}$ Nutritional status also bears a significant influence on wound healing and immune function in surgical patients in general. Left ventricular assist devices (LVADs) have become an acceptable mode of bridge to transplantation for patients with end-stage heart failure. We propose to study the course of nutritional status in patients receiving LVAD support and correlate this with their clinical outcomes.

\section{Patients and Methods}

Ninety-nine patients undergoing LVAD implantation from January 1996 through February 2003 were retrospectively reviewed. Patients were evaluated according to 4 preoperative nutritional parameters: serum albumin level, total protein (TP) level, absolute lymphocyte count (ALC; white cell count $\times$ percentage lymphocytes), and body mass index (BMI). Each parameter was categorized as low or normal according to our patient population's value range: albumin, 3.5 to $5.3 \mathrm{~g} / \mathrm{dL}$; $\mathrm{TP}, 6.0$ to $8.5 \mathrm{~g} / \mathrm{dL}$; ALC, 0.85 to $4.10 \times 10^{3} / \mathrm{mL}^{3}$; and BMI, 20 to $25 \mathrm{~kg} / \mathrm{m}^{2}$. Low and normal groups were then compared with regard to demographics, devicerelated infections, bridge-to-transplantation rate, total hospital and intensive care unit (ICU) length of stay (LOS), and posttransplantation survival.

Data were represented as frequency distributions and percentages. Values of continuous variables were expressed as means \pm standard deviation. Continuous variables were compared with independent samplest tests, whereas nominal variables were compared with $\chi^{2}$ and Fisher exact tests. Parameters at consecutive time points were compared with repeated-measures analysis of variance tests. All data were analyzed with SPSS 11.5 software (SPSS, Inc, Chicago, Ill).

\section{Results}

Demographics. Clinical characteristics and outcomes are shown in Table 1. Patients with low ALCs were older than those

From Columbia University, College of Physicians and Surgeons, Department of Cardiothoracic Surgery, New York, NY.

Received for publication July 3, 2005; revisions accepted July 18, 2005; accepted for publication July 19, 2005.

Address for reprints: Yoshifumi Naka, MD, PhD, Division of Cardiothoracic Surgery, New York-Presbyterian Hospital, Columbia University Medical Center, 177 Fort Washington Ave, Milstein Hospital 7GN-435, New York, NY 10032 (E-mail: yn33@columbia.edu).

J Thorac Cardiovasc Surg 2005;130:e3-e4

$0022-5223 / \$ 30.00$

Copyright $\odot 2005$ by The American Association for Thoracic Surgery

doi:10.1016/j.jtcvs.2005.07.038 with normal ALCs, but there were otherwise no differences in age or sex distribution across nutritional parameter subgroups.

Nutritional parameter trends on LVAD support. The mean values of all nutritional parameters were obtained preoperatively and then postoperatively at 1, 2, and 3 months and are shown in Figure 1. By 3 months, mean serum albumin levels increased to within normal limits, mean TP levels increased (although not significantly), and there was a trend toward decreasing mean ALC and BMI.

Postoperative infection rates and LOS. Among postoperative device-related infections, patients with low ALCs had a higher rate of sepsis than those with normal ALCs. There were no differences in infection rates between subgroups for any of the other parameters. The overall rates of sepsis and any type of infection were $14.1 \%$ and $50.5 \%$, respectively. Mean total hospital LOS was equivalent among subgroups, but mean ICU LOS was significantly longer in patients with low serum albumin and TP levels than in those with normal values.

Bridge-to-transplantation rate and posttransplantation survival. The bridge-to-transplantation rate was significantly lower in patients with low serum albumin and TP levels than in those with normal values (Table 1). Posttransplantation actuarial survivals at 1,3 , and 5 years were equivalent among all subgroups.

\section{Discussion}

In this study low preoperative serum albumin level, TP level, and ALC were associated with poor clinical outcomes, including a higher rate of sepsis, lower bridge-to-transplantation rate, and longer ICU LOS. In patients with LVAD support, particularly the elderly, the consequences of poor nutritional status are decreased immune function, higher infection rates, and impaired wound healing. Physical conditioning and rehabilitation efforts might also be compromised, contributing to diminished survival in the acute recovery period.

The increase in serum albumin levels over time might reflect amelioration of the chronic inflammatory state with a shift away from protein catabolism. This is likely augmented by rehabilitation on LVAD support and increased nutritional intake. The trend toward a decrease in ALC over time might relate to CD4 T-cell apoptosis induced by direct contact of the biosynthetic membrane in certain pulsatile LVADs with elements of the blood circulation. ${ }^{3}$ This process can generate defects in cellular immunity, placing patients at even greater risk of infection. The trending decrease in BMI with LVAD support likely represents loss of edematous fluid facilitated by enhanced renal flow.

The practice of nutritional assessment in patients with LVAD support has been examined previously ${ }^{4}$ and continues to carry great importance. Nutritionally at-risk patients should be identified preoperatively and supplemented according to individual caloric and substrate needs. Nutritional optimization should continue well into the intermediate postoperative period. 
TABLE 1. Demographics and clinical characteristics

\begin{tabular}{|c|c|c|c|c|c|c|c|c|c|c|c|c|}
\hline & $\begin{array}{c}\text { Alb < } \\
3.5 \mathrm{~g} / \mathrm{dL} \\
(\mathrm{n}=36)\end{array}$ & $\begin{array}{c}\text { Alb } \geq \\
3.5 \mathrm{~g} / \mathrm{dL} \\
(\mathrm{n}=63)\end{array}$ & $\begin{array}{c}\boldsymbol{P} \\
\text { value }\end{array}$ & $\begin{array}{c}\mathrm{TP}< \\
6.0 \mathrm{~g} / \mathrm{dL} \\
(\mathrm{n}=14)\end{array}$ & $\begin{array}{c}\mathrm{TP} \geq \\
6.0 \mathrm{~g} / \mathrm{dL} \\
(\mathrm{n}=85)\end{array}$ & $\begin{array}{c}\boldsymbol{P} \\
\text { value }\end{array}$ & $\begin{array}{c}\text { ALC }<0.85 \times \\
10^{3} / \mathrm{mL}^{3} \\
(\mathrm{n}=33)\end{array}$ & $\begin{array}{c}\text { ALC } \geq 0.85 \times \\
10^{3} / \mathrm{mL}^{3} \\
(\mathrm{n}=66)\end{array}$ & $\begin{array}{c}P \\
\text { value }\end{array}$ & $\begin{array}{c}\text { BMI }<20 \\
\mathrm{~kg} / \mathrm{m}^{2} \\
(\mathrm{n}=6)\end{array}$ & $\begin{array}{c}\text { BMI } \geq 20 \\
\mathrm{~kg} / \mathrm{m}^{2} \\
(\mathrm{n}=93)\end{array}$ & $\begin{array}{c}P \\
\text { value }\end{array}$ \\
\hline Age (y) & $54 \pm 10$ & $49 \pm 12$ & .21 & $53 \pm 12$ & $51 \pm 12$ & .51 & $56 \pm 8$ & $48 \pm 13$ & .01 & $46 \pm 23$ & $51 \pm 11$ & .29 \\
\hline $\operatorname{Sex}(F)$ & $13.9 \%$ & $9.5 \%$ & .36 & $14.3 \%$ & $10.6 \%$ & .48 & $15.2 \%$ & $9.1 \%$ & .28 & $16.7 \%$ & $10.8 \%$ & .52 \\
\hline \multicolumn{13}{|l|}{ Infection } \\
\hline Driveline & $8.3 \%$ & $6.3 \%$ & .50 & $7.1 \%$ & $7.1 \%$ & .67 & $6.1 \%$ & $7.6 \%$ & .57 & $0.0 \%$ & $7.5 \%$ & .64 \\
\hline Pocket & $8.3 \%$ & $23.8 \%$ & .06 & $14.2 \%$ & $18.8 \%$ & .51 & $18.2 \%$ & $18.2 \%$ & .62 & $16.7 \%$ & $18.3 \%$ & .70 \\
\hline Pump & $11.1 \%$ & $7.9 \%$ & .42 & $7.1 \%$ & $9.4 \%$ & .63 & $6.1 \%$ & $10.6 \%$ & .37 & $0.0 \%$ & $9.7 \%$ & .56 \\
\hline Sepsis & $22.2 \%$ & $9.5 \%$ & .08 & $28.6 \%$ & $11.8 \%$ & .11 & $24.2 \%$ & $9.1 \%$ & .04 & $0.0 \%$ & $15.1 \%$ & .39 \\
\hline Any & $50.0 \%$ & $50.8 \%$ & .55 & $57.1 \%$ & $49.4 \%$ & .40 & $48.5 \%$ & $51.5 \%$ & .47 & $50.0 \%$ & $50.5 \%$ & .65 \\
\hline BTT & $66.7 \%$ & $84.1 \%$ & .04 & $57.1 \%$ & $81.2 \%$ & .05 & $72.7 \%$ & $80.3 \%$ & .27 & $83.3 \%$ & $77.4 \%$ & .60 \\
\hline Total LOS (d) & $36 \pm 9$ & $30 \pm 20$ & .27 & $36 \pm 34$ & $31 \pm 22$ & .51 & $30 \pm 20$ & $33 \pm 26$ & .57 & $25 \pm 20$ & $33 \pm 24$ & .47 \\
\hline ICU LOS (d) & $21 \pm 25$ & $12 \pm 12$ & .01 & $26 \pm 36$ & $13 \pm 12$ & .01 & $15 \pm 15$ & $15 \pm 20$ & .98 & $12 \pm 8$ & $15 \pm 18$ & .65 \\
\hline
\end{tabular}

$A l b$, Albumin; TP, total protein; $A L C$, absolute lymphocyte count; $B M I$, body mass index; $B T T$, bridge to transplantation; $L O S$, length of stay; ICU, intensive care unit.

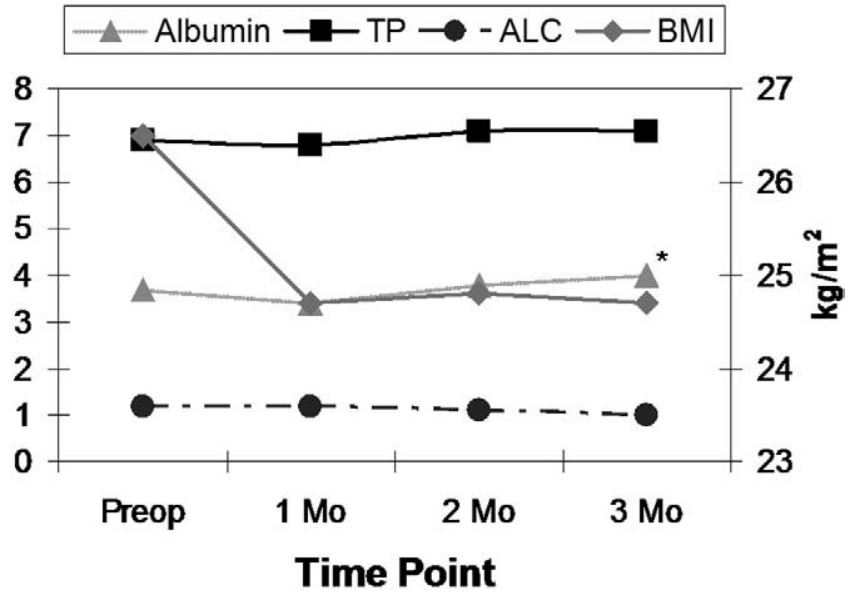

Figure 1. The mean values of all nutritional parameters obtained preoperatively and then postoperatively at 1, 2, and 3 months. TP, Total protein; ALC, absolute lymphocyte count; BMI, body mass index; Preop, preoperative period. ${ }^{*} \boldsymbol{P}<.05$.
Study limitations include those inherent with retrospective analyses. Moreover, with an overall study sample size of only 99 patients and even fewer numbers within the nutritional parameter subcategories, the potential for type II error within individual analyses is appreciable.

In conclusion, malnutrition predisposes to poor clinical outcomes, although protein status improves with LVAD support. Efforts should be made to identify patients at risk and provide nutritional supplementation throughout the perioperative period.

\section{References}

1. Mustafa I, Leverve X. Metabolic and nutritional disorders in cardiac cachexia. Nutrition. 2001;17:756-60.

2. Aquilani R, Opasich C, Verri M, Boschi F, Febo O, Pasini E, et al. Is nutritional intake adequate in chronic heart failure patients? J Am Coll Cardiol. 2003;42:1218-23.

3. John R, Lietz K, Schuster M, Naka Y, Rao V, Mancini DM, et al. Immunologic sensitization in recipients of left ventricular assist devices. J Thorac Cardiovasc Surg. 2003;125:578-91.

4. Vega JD, Poindexter SM, Radovancevic B, Burnett CM, Lonquist JL, Birovljev S, et al. Nutritional assessment of patients with extended left ventricular assist device support. ASAIO Trans. 1990;36:M555-8. 